\title{
Mechanism of Carbon Finance's Influence on Radical Low-Carbon Innovation with Evidence from China
}

\author{
Limei Sun ${ }^{1}$, Jinyu Wang ${ }^{1}$, Zhicheng Wang ${ }^{2, *}$ and Leorey Marquez ${ }^{3}$ (I) \\ 1 School of Economics and Management, Harbin Engineering University, Harbin 150001, China; \\ slm0451@163.com (L.S.); sunlimei@hrbeu.edu.cn (J.W.) \\ 2 Education Foundation, Renmin University of China, Beijing 100086, China \\ 3 Data61, CSIRO, Clayton, Victoria 3168, Australia; leorey.marquez@data61.csiro.au \\ * Correspondence: wangzhicheng2003@ruc.edu.cn
}

Received: 20 August 2020; Accepted: 15 September 2020; Published: 18 September 2020

\begin{abstract}
Radical low-carbon innovations have considerable technological and revolutionary influences. These key technologies considerably reduce carbon dioxide emissions. This study examines the role of carbon finance development in China's radical low-carbon innovations. The paper identifies the key entities involved, constructs a network model of the interaction between carbon finance and radical low-carbon innovation, and uses multi-agent simulation modeling to analyze the associated influence mechanism. The results demonstrate that the carbon market can promote radical low-carbon innovation by (1) regulating the number of enterprises participating subject to carbon emission regulations, (2) regulating the number of market intermediaries, (3) establishing the market regulation level, and (4) setting the carbon intensity reduction level. The paper concludes that the Chinese government can formulate novel carbon market-related policies and regulations that, in a timely manner, influence the relationship between the carbon market and participating entities to promote the development of radical low-carbon technologies.
\end{abstract}

Keywords: carbon finance; radical low-carbon innovation; complex network

\section{Introduction}

The acceleration of industrialization is one of the primary factors exacerbating climate change. The environmental problems resulting from unregulated economic development have the potential to threaten human survival leading many countries to attach immense importance to the development of green industries. These governments regard advanced energy conservation and environmental protection technologies as core capabilities that need to be actively cultivated for competitiveness.

The international green industry market is dominated by a few industrialized countries. The output value of the United States, the European Union, and Japan combined, accounts for more than $80 \%$ of total global output. As one of the national governments addressing the United Nations Framework Convention on Climate Change, China has pledged to reduce domestic carbon dioxide emissions per unit of GDP by $60-65 \%$ from the 2005 level by 2030. However, China is at a critical stage of economic transformation, and the benefit of demographic dividends is no longer distinct [1]. China's low-carbon technology innovation is deemed unsatisfactory.

Patents, as an indicator of technological innovation, have been used in numerous recent studies to evaluate technological innovation capabilities [2-5]. According to the National Intellectual Property Administration, China is one of the top countries in terms of the number of low-carbon patent applications in recent years. However, ownership of many of the patent rights do not belong to domestic entities. China's domestic institutions account for only $40 \%$ of the top 20 low-carbon technology patent applications. The low-carbon industry in China has largely followed the development 
model of conventional manufacturing and has not adequately developed the top core technologies [6]. This indicates that China has still considerable scope for improvement in terms of low-carbon technology innovation capabilities.

Unlike incremental innovation, radical innovation emphasizes discontinuity in development. This discontinuity is reflected in two aspects. Firstly, the discontinuity in trajectory or the departure from existing innovation results in the realization of a technological leap. Secondly, there is a discontinuity in the market manifested in the targeting of new consumer groups and the development of new markets. Radical low-carbon innovation is characterized by long research and development cycles, high capital requirements, high investment risks, and uncertain investment returns [7]. Substantial, stable, and sustained capital investment is indispensable to the development of the industry. Carbon finance is a market-based solution [8] aimed at reducing the negative effects of climate change [9] through the carbon emission trading mechanism. By internalizing pollution, an external issue [10], carbon finance stimulates original low-carbon technology development and helps achieve sustainable economic development [11].

Recent research indicates that the role of different financing methods in technological innovation is still controversial. Carbon finance is an emerging financial instrument and its relationship with radical low-carbon innovation has significant differences compared with those from conventional financial instruments. Researchers have analyzed the role of carbon finance in reducing carbon dioxide emissions and have shown that it is more efficient and less costly than other emission reduction methods [12-14]. Some of the research focuses on the economic, social and environmental impacts of low carbon innovation $[15,16]$. The correlation of finance and low carbon innovation has also been gradually highlighted $[17,18]$. Carbon finance will affect technological innovation through corporate governance, risk diversification, and information transfer $[19,20]$. One perspective holds that bank-based indirect finance promotes technological innovation by providing the necessary capital for the reorganization of production factors for enterprise innovation and supervising enterprises [21-23]. A second view suggests that banks are risk-averse to technological innovation, especially those related to radical innovation projects, due to the banks' objective of achieving stable returns. Therefore, credit support is difficult to obtain, obstructing the development of radical technological innovation [24]. Furthermore, the multiple principal-agent and multitask characteristics of indirect finance hinder the marketization of enterprise technology innovation, which is not conducive to enterprises engaging in technological innovation [25-28].

Two views are held on the role of direct finance. Kortum and Atanassov assert that direct finance enhances the efficiency of an enterprise's innovative behavior $[29,30]$, thus improving the conversion rate of technological innovation into economic benefits. Compared with banks, the capital market appear to better promote technological innovation [31,32]. However, some scholars dispute this view and assert that the information asymmetry of direct finance brings agency risk and moral hazard, increasing the cost of financing innovative enterprises and making it less conducive to technological innovation [33].

While several studies have discussed the positive effect of carbon finance on low-carbon technological innovation, no studies have revealed the mechanism of influence between the two or have presented systematic findings using the current research approach [34-42]. This study is the first to investigate this issue and makes contributions in the following areas. Firstly, this study extends our understanding of the theoretical basis for radical low-carbon innovation by presenting additional analyses of its content and characteristics. Secondly, the study constructs a network model mapping the mechanism of interaction between carbon finance and radical low-carbon innovation. The effect of carbon finance on radical low-carbon innovation is neither passive nor singular; rather, its influence is propagated through a series of major actors and pathways that resembles that of a complex network. Finally, the paper demonstrates the mechanism of influence using a multi-agent simulation system. 


\section{Complex Network Analysis}

Complex networks originated from Euler's graph theory and topological theory [43], and are frame graphics generalized from the complex system. They consist of two basic components, namely, nodes and edges, which represent items in a system and the relationships between them, respectively. Networks have different characteristics; hence, choosing an appropriate network model as the theoretical basis for research is crucial. The complex network concept was created from regular networks; its subsequent advancement led to the development of diverse networks, including the regular network, the Erdös-Rényi random network, the Watts-Strogatz small world network, and the Barabási-Albert (BA) scale-free network. The complexity of these networks has progressively increased to resemble real-life connections. In recent years, complex networks have been applied in numerous fields, such as logistical network optimization [44-46], and urban transportation [47,48].

Achieving radical low-carbon innovation is part of the basic research and development and talent cultivation function of higher education and scientific institutions. As a market-oriented instrument for lessening air pollution and improving the environment, carbon finance must be implemented through market trading entities. To understand the mechanism by which carbon finance influences radical low-carbon innovation, this study focuses on the complex network consisting of five entities, namely higher education and scientific research institutions and four trading entities (market organizations, regulators, intermediaries, traders). As the network is open and scale-free, this study adopts the BA scale-free network model. The market trading entities are described as follows.

\subsection{Carbon Market Organizations}

To meet its emission reduction commitments, China established the National Development and Reform Commission (NDRC). The NDRC aims to ensure the successful development and implementation of Clean Development Mechanism (CDM) projects and to stabilize China's newly established regional carbon trading market. The CDM Management Center was established under the NDRC as the subsidiary institution responsible for CDM project development. The NDRC also created the CDM Fund Management Center to provide financial support for relevant academic and policy research and to review $\mathrm{CDM}$ projects.

\subsection{Carbon Market Regulators}

Carbon market regulators include carbon trade exchange and carbon emission verification institutions. These institutions assume regulatory responsibilities for the carbon market. The carbon trade exchange has three major responsibilities, namely providing information on carbon trading; formulating specific trading rules and procedures for liquidation and delivery, regulating carbon trading behavior, and maintaining order in the carbon market; and engaging in the design and innovation of carbon-related products. The role of the carbon emission verification agency is to review and assess the content, veracity and accuracy of carbon emissions reports submitted by companies and enterprises.

\subsection{Carbon Market Intermediaries}

Depending on business operations, intermediaries in the carbon market can include commercial banks, insurance companies, securities companies, mutual fund companies, and law firms. Banks provide four types of services in the carbon market. First, they provide credit support and mortgage guarantees for loan-related transactions that satisfy low-carbon standards. Second, they provide finance consultation services for enterprises undertaking CDM projects. Third, banks serve as agents for parties involved in a transaction. Finally, they provide finance and leasing services to enterprises requiring equipment for reducing carbon emissions or energy consumption. Insurance companies participate in carbon trading by providing carbon-trading-related insurance products and diversifying 
the risks related to trading. Securities companies also provide innovative low-carbon financial products such as forest bonds and ecology-related securities.

\subsection{Carbon Market Traders}

Two types of traders operate in the carbon market, namely speculative institutions and individual investors. Institutions investing in carbon emission rights develop CDM items in cooperation with other institutions and can obtain certified emission reductions (CERs) following item review by relevant government departments. Institutions can obtain investment returns by engaging in transactions related to CER obtained through CDM projects. They can also use carbon-related financial derivatives such as carbon futures, carbon emission options, and forward contracts to manage asset risks and achieve the preservation and appreciation of assets.

Individual investors obtain profits from price fluctuations by analyzing carbon market information. Investors can hedge risks using carbon futures, insurance, and forward trading, and achieve asset preservation and appreciation while enhancing carbon market liquidity.

\subsection{Entities Participating in Technological Innovation}

The primary technological innovation entities are enterprises, higher education institutions, and scientific research and development institutions. Before the implementation of the carbon finance system, environmental pollution generated by manufacturers was considered an external problem, and manufacturers disregarded this issue. Following the implementation of the carbon finance system, relevant government agencies began supervising the carbon emissions of manufacturers. In response to increasing environmental regulations, manufacturers have responded in two ways. Some have reduced production to control emissions and satisfy emission regulations using existing production technologies and methods. Others have chosen to develop or apply new technologies to manufacture products or, to modify existing energy-intensive production methods to reduce carbon emissions for each product unit.

\section{Constructing the Carbon Trading Network}

To define the carbon trading network, let $N=(D, S)$, where $D(N)$ represent the set of all nodes I, J that comprise the network, that is $I, J \in D(N) . S(N)$ is the set of all edges $e_{I J}$ in the network, indicating the connections between all the nodes, and $e_{I J}$ represents the link of connecting nodes I and J with $e_{I J} \in S(N), I, J \in D(N)$. A representation of the market network is shown in Figure 1 . The following node symbols were used to denote various network entities: Market organizations $(A)$, intermediaries $(C)$, and transaction entities $(D)$. The entities of innovation include higher education $(D)$ and scientific research institutions (E). The NDRC (A1), CDM Management Center $(A 2)$, and the CDM Fund Management Center $(A 3)$ are also involved in the carbon market. Management institutions include regional carbon trade exchange (B1) and a third-party verification unit (B2). Intermediaries include commercial banks ( $C 1)$, insurance companies (C2), securities companies (C3), mutual fund companies (C4), and law firms (C5). Transaction entities include enterprises subject to carbon emission regulations $(D 1)$ and enterprises participating in speculative carbon trading (D2). 


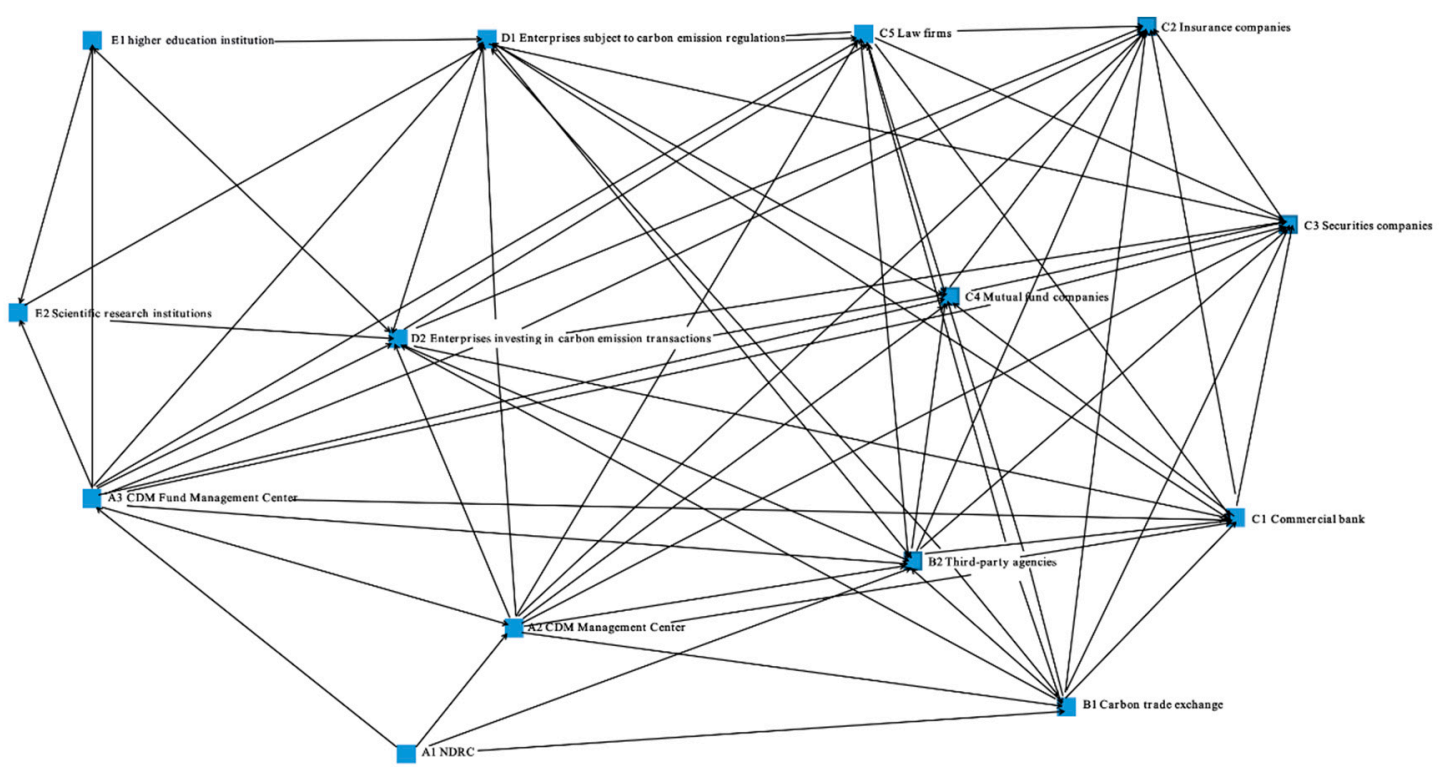

Figure 1. Network model of the influence of carbon finance on radical low-carbon innovation with nodes representing market organizations (A1-A3, B1-B2), intermediaries (C1-C5), transaction entities (D1-D2), higher education (E1) and scientific research institutions (E2).

The network relationship between the entities is represented by a binary matrix. If entity $I$ markedly influences the interests of entity $J$, the $I$ th row and $J$ th column are set as 1 ; otherwise, they are set as 0 .

\section{Multi-Agent Simulation Operation and Analysis}

\subsection{Analysis of Agent Behavior}

An agent in the network is an entity capable of specific behavior and can be equipped with learning abilities. Agent types are constructed from observing real-life targets, determining their specific behavior patterns, and then writing software to mimic the target and perform simulations with it. Multi-agent systems are intelligent systems composed of several autonomous and dynamic agents. By decomposing tasks, complex problems can be simplified and solved. The following sections describe the attributes and behavior of various carbon finance entities.

\subsubsection{Enterprises}

Enterprises are key to technological innovation and are entities faced with carbon emission restrictions. In the multi-agent model used in this study, an enterprise has three attributes, namely, wealth, patents, and productivity. In the initial state, several enterprises are set as the main entities; their net worth, number of radical patents, and production capacity are set to an integer greater than zero but less than 10. The government allocates carbon emission licenses according to the carbon emission reduction intensity and production capacity of the enterprise. For example, when the government-regulated carbon emission reduction intensity is set to be 0.9 , for an enterprise with a production capacity of 10 , the allocated carbon emission license would be 9 units $(10 \times 0.9=9)$. We also assume that the coefficient for the effect of number of patents on carbon emission reduction is 0.2 (i.e., having 10 patents results in a carbon emission reduction of 2 units in the production process) [49]. Therefore, in the previous example, the company is facing a shortfall of 1 carbon emission unit. However, if the company possesses 5 units of radical low-carbon patents, it can meet its carbon emission cap of 9 units without having to reduce its production capacity. If the company's number of radical low-carbon patents is greater than 5 , the amount of carbon emissions it needs will be less than 9, the company can sell its surplus carbon emission license in the carbon market following production. 
Alternatively, if the number of relevant patents is fewer than 5 units, then the company must purchase carbon emission license units from the carbon market. Failure to do so would result in the company's eviction from the market by the carbon emission regulators upon the company's exhaustion of their carbon emission license units.

\subsubsection{Higher Education and Scientific Research Institutions}

In the multi-agent model, higher education and scientific research institutions represent the institution agents or ins-agents. They have three attributes, namely number of low-carbon patents, research and development funds, and innovation capability. In the initial state, several institution agents are set. In addition, the number of patents of each institution agent is set to 0 and the innovation capability is a random number between 0 and 10. The government allocates research and development funding according to the institution's innovation capability; in this study, 0.0652 is set as the coefficient for converting research and development funding to the number of patents based on the approach of Luo Zhi [50]. Under normal circumstances, enterprises undertake joint innovation activities with other research institutions through cooperation or commissioned research and share resources in the innovation network.

\subsubsection{Market Organizations}

Market organizations manage trading in the carbon market and allocate carbon allowances. This study establishes the government agent to represent a market management institution. Assuming that the operating environment is a unified carbon financial market, the number of market organizations is set to 1 . In the initial state, the market organization allocates carbon emission licenses and research funding to higher education and scientific research institutions according to the carbon allowance at the time.

\subsubsection{Market Regulators}

Market regulators supervise the behavior of market transaction entities and are represented by supervisor agents. When the market regulator perceives a transaction-related violation, they impose sanctions on the offending entity. When an enterprise's license units are insufficient but the enterprise remains unwilling to buy additional license units from the carbon market, that enterprise agent shall be removed from the model by the supervisor agent.

\subsubsection{Market Intermediaries}

Market intermediaries can advance transactions that would otherwise fail due to information asymmetry and a lack of channels; hence, market intermediaries play an active role in the market. A large number of market intermediaries is conducive to successful carbon emission license transactions. This study uses the medi-agent as intermediary agents and assumes $\mathrm{n} \times 0.1$ is the coefficient for the number of market intermediaries to the number of successful license transactions.

\subsection{Simulation of Market Behavior}

Using Netlogo, we build the simulation model. The initial state of the model is set as follows. The size of the simulation space is $20 \times 20$, and the five types of entities are randomly allocated in this space, with each occupying one tile. One market regulator agent and one market organization agent are set. The numbers of enterprises and institution agents are set as 100 and 50, respectively. The number of intermediary institutions can be adjusted using the control bar. At each time step, each entity in the simulation system randomly moves according to the behavior pattern specified by the programming code to conduct carbon emission license trading and innovation activities. When the operating time satisfies a specific condition, the system stops running and the simulation process is terminated. The simulation results can then be observed as figures. In this model, the number of 
runs is set to 300 , based on real-life actual observations. The user interface for performing the market simulation in NetLogo is shown in Figure 2.

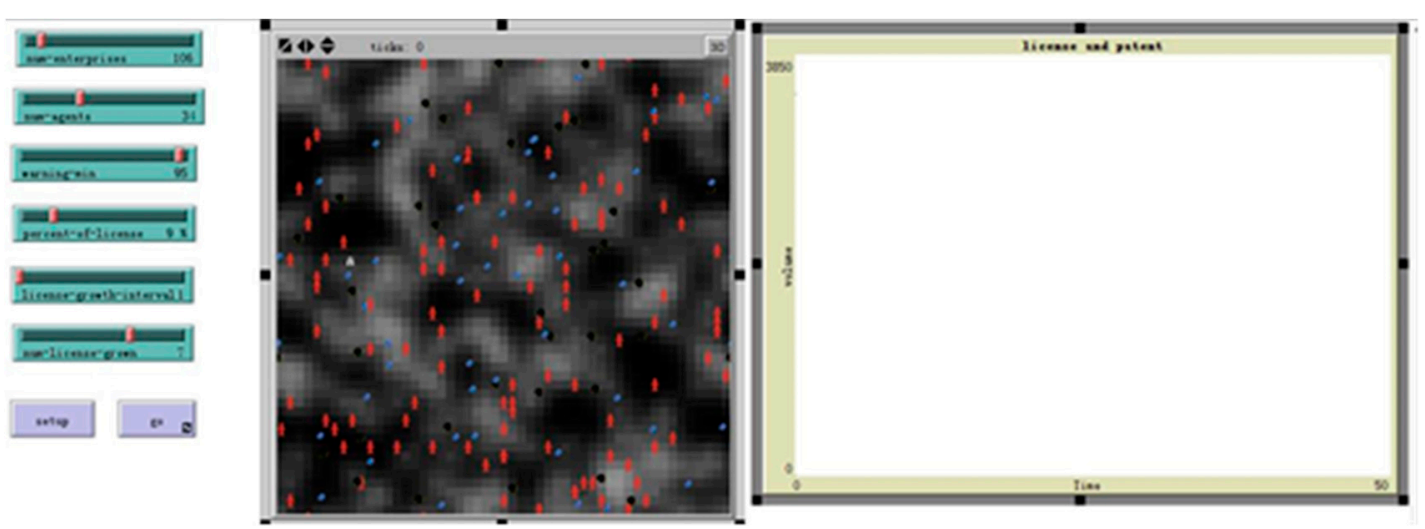

Figure 2. Simulation of carbon trading market using NetLogo.

\subsection{Analysis of Multi-Agent Operation Results}

\subsubsection{Impact of Enterprises on Innovation}

Figure 3 presents the impact of the number of regulated enterprises on carbon license transaction volumes and the number of radical low-carbon innovation achievements. In Figure 3a, the number of regulated enterprises is 50, the number of carbon emission license transactions is 510,000, and the number of radical low-carbon innovations is 2937. In Figure 3b, the number of regulated enterprises is 100 , the number of carbon emission license transactions is 696,000 , and the number of radical low-carbon innovations is 4309 .

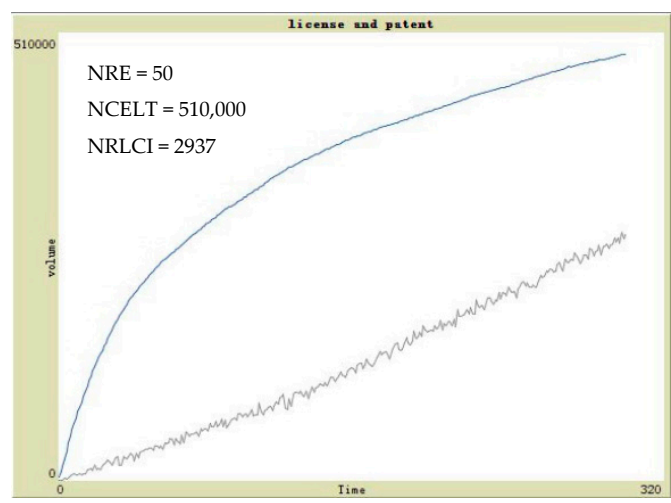

(a)

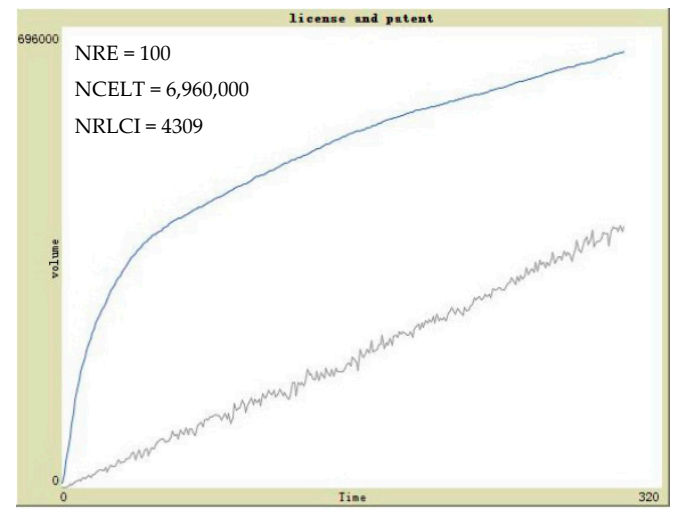

(b)

Figure 3. Performance of the number of carbon emission license transactions (NCELT) and number of radical low-carbon innovation (NRLCI) in simulations using (a) a small number of regulated enterprises $(\mathrm{NRE}=50)$, and $(\mathbf{b})$ a high number of regulated enterprises $(\mathrm{NRE}=100)$.

A comparative analysis of the results displayed in Figure 3 reveals that with other conditions remaining constant, increasing the number of regulated enterprises will increase the number of carbon market transactions, leading to a more active carbon market and more radical low-carbon innovations. The simulation demonstrates that a large number of regulated enterprises is conducive to expanding the carbon market and promoting the effects of carbon finance on the development of radical low-carbon innovations. This means that the number of regulated enterprises is a major factor affecting carbon emission license trading and radical low-carbon innovation. 
In general, carbon market organizations decide which companies or industries should be subject to emission regulations. However, in China, such decisions are made by government institutions such as the NDRC and CDM Management Center. Therefore, relevant government institutions in China can influence the development of radical low-carbon innovation by regulating the number and scope of companies that should be subject to relevant emission regulations.

\subsubsection{Impact of Market Intermediaries}

Figure 4 presents the impact of changes in the number of market intermediaries on the number of carbon emission license transactions and the number of radical low-carbon innovations when other conditions are held constant. Figure 4a shows that when the number of market intermediaries is 10, the number of carbon emission license transactions is 723,000 and the number of radical low-carbon innovations is 1963 . Figure $4 \mathrm{~b}$ shows that when the number of market intermediaries is increased to 50 , the number of carbon emission license transactions rises to 861,000 and the number of radical low-carbon innovations becomes 3479. This indicates that, given other conditions are constant, increasing the number of market intermediaries leads to increased transactions in the carbon market and more radical low-carbon innovations. This indicates that the number of market intermediaries is a crucial factor affecting radical low-carbon innovation. By reducing conflicts in the market, market intermediaries enhance liquidity thereby rendering the market more active, increasing the number of carbon emission license transactions and influencing the direction of enterprise investment and financing. This condition promotes innovative behavior in enterprises. Thus, maintaining a large number of high-quality carbon market institutions will lead to an active carbon market that will be conducive to radical low-carbon innovations.

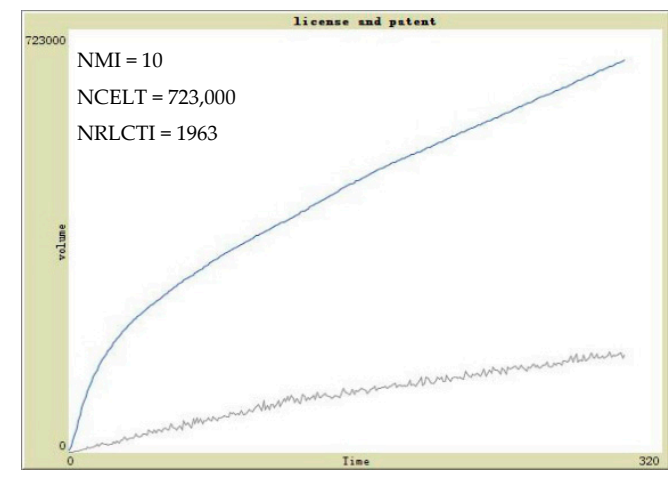

(a)

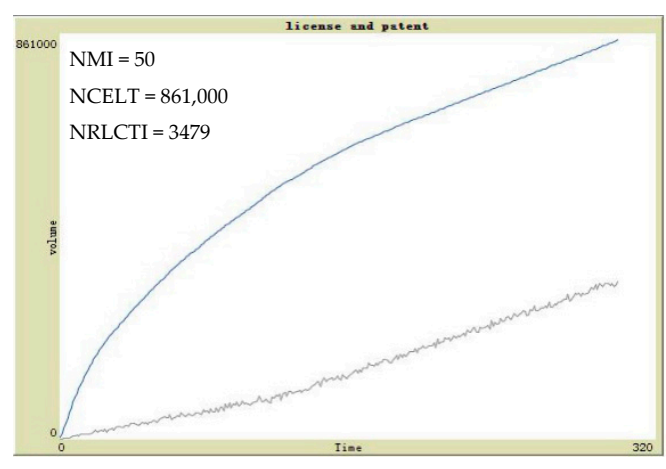

(b)

Figure 4. Performance of the number of carbon emission license transactions (NCELT) and the number of radical low-carbon innovation (NRLCI) in simulations using (a) a low number of market intermediaries $(\mathrm{NMI}=10)$, and $(\mathbf{b})$ a high number of market intermediaries $(\mathrm{NMI}=50)$.

\subsubsection{Impact of Carbon Intensity Reduction}

Figure 5 shows the impact of carbon intensity reduction on the number of carbon emission license transactions and radical low-carbon innovations while other conditions are constant. The government-stipulated carbon allowance is the main reference indicator for carbon intensity reduction levels. In Figure 5a, the carbon allowance is $90 \%$ of the original emission level. At this level, the number of carbon emission license transactions is 702,000 and the number of radical low-carbon innovations is 2463 . As Figure $5 \mathrm{~b}$ shows, when the carbon allowance is decreased to $85 \%$ of the original emission level, the resulting number of carbon emission license transactions rises to 1,460,000, and the number of radical low-carbon innovations climbs to 3047. Similarly, in Figure 5c, when the carbon allowance is set to $80 \%$ of the original emission level, the number of carbon emission license transactions becomes 964,000 and the number of radical low-carbon innovations is 2466 . 


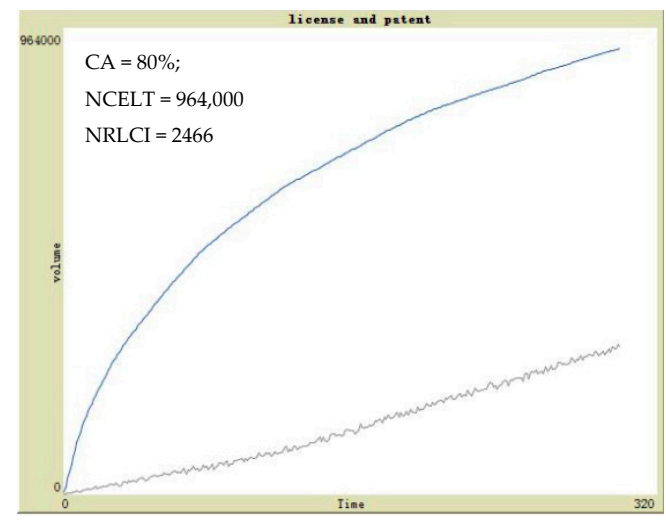

(a)

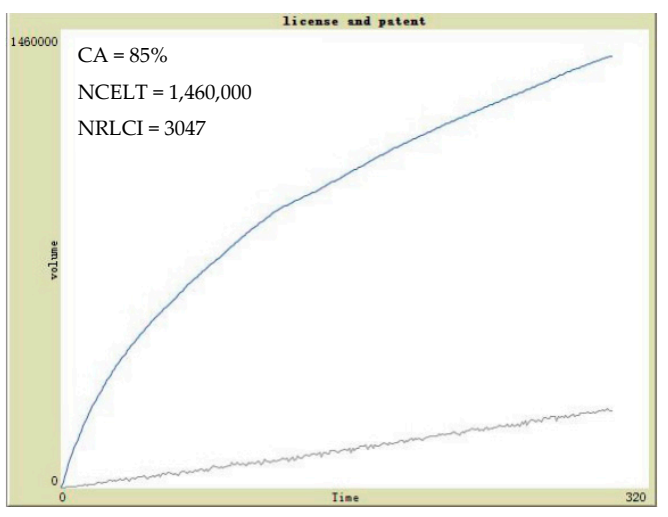

(b)

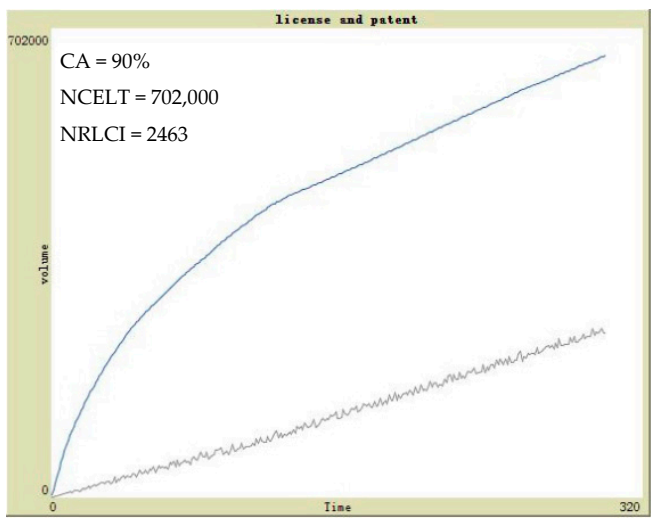

(c)

Figure 5. Performance of the number of carbon emission license transactions (NCELT) and the number of radical low-carbon innovation (NRLCI) under three levels of carbon allowance (CA) - (a) a low level of carbon intensity reduction $(\mathrm{CA}=80 \%),(\mathrm{b})$ a moderate level of carbon intensity reduction $(\mathrm{CA}=85 \%)$, and $(\mathrm{c})$ a high level of carbon intensity reduction $(\mathrm{CA}=90 \%)$.

Figure 5 indicates that the number of carbon emission license transactions and that of radical low-carbon innovations have an inverted U-shaped relationship with carbon allowance. Under low carbon intensity reduction and a high carbon allowance, the number of transactions decreases along with a decrease in innovations. With an increase in carbon intensity reduction and a decrease in carbon allowance, the number of transactions and innovations increases. However, with a further increase in carbon intensity reduction and a decrease in carbon allowance, the number of transactions and innovations also decrease. This suggests that the carbon intensity reduction level is a crucial factor influencing the number of carbon emission license transactions and radical low-carbon innovations. The Chinese government's emission reduction plans influence the carbon emission reduction intensity and help determine the initial number of licenses to be issued. Through appropriate adjustment to carbon intensity reduction levels, the promotion of radical innovations through carbon finance can be maximized.

\subsubsection{Impact of Market Regulations}

Figure 6 presents the impact of market regulations on the number of carbon emission license transactions and radical low-carbon innovations. When the market regulation level is 8 , the number of carbon emission license transactions is $1,240,000$, and the number of radical innovations that remain is 2089. When the market regulation level is increased to 50 , the number of carbon emission license transactions rises to 1,500,000 and the number of radical innovations increases to 3484 . This reveals that the number of license transactions and radical innovations increase with market regulation level. 
This suggests that the regulation intensity of related institutions is conducive to generating desirable entrepreneurial behavior, establishing market order, and encouraging enterprises to engage in radical innovations and update their production methods. Using green low-carbon production methods, enterprises can lower their carbon emission levels and meet their emission caps, in turn promoting radical innovations. By modifying the operation direction and level of implementation, China's finance market regulators (i.e., carbon trade exchange and carbon emission verification institutions) can influence carbon market trading and radical innovations.

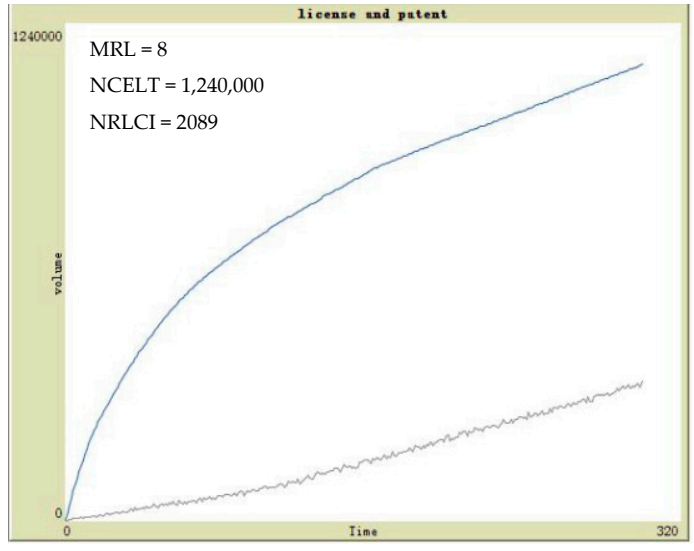

(a)

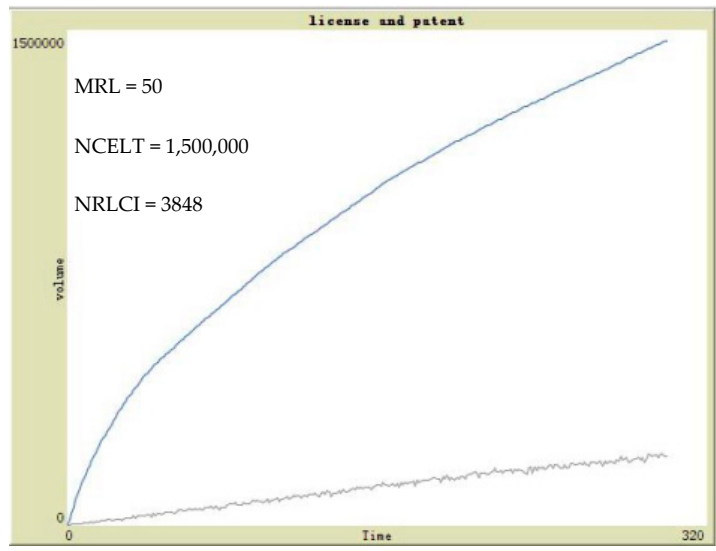

(b)

Figure 6. Performance of the number of carbon emission license transactions (NCELT) and the number of radical low-carbon innovation (NRLCI) in simulations using (a) a low market regulation level $(\mathrm{MRL}=8)$, and $(\mathbf{b})$ a high market regulation level $(\mathrm{MRL}=8)$.

\section{Conclusions}

In this study, a network model was constructed to understand and simulate the impact of carbon finance on radical low-carbon innovation by using agents to represent related entities. The simulation results reveal that the number of entities participating in carbon emission trading increases with an increase in the number of regulated enterprises and this increase is conducive to the prosperity of the carbon market and the development of radical low-carbon innovations. Changes in the number of market intermediaries and regulation levels lead to corresponding directional changes in the development of radical low-carbon innovations.

However, carbon intensity reduction has an inverted U-shaped relationship with radical low-carbon innovation development. The development level of radical innovations is low when carbon intensity reduction is low. Radical innovations increase when carbon intensity reduction is moderate but decrease when the reduction level is further increased.

Four approaches can be taken to promote the development of radical low-carbon innovations through carbon finance. Firstly, a scientific mechanism for allocating carbon emission licenses should be established to increase the range of industries subject to emission regulations. With more enterprises being subjected to emission regulations, the carbon market can be vitalized.

Secondly, a comprehensive market regulation mechanism, along with protection, incentives, and penalty mechanisms, should be established to ensure the orderly operation of the carbon market. Warning signals can be issued when the risk of structural adjustment in the carbon finance industry increases. Supervision should be provided to ensure that preferential policies, such as those related to government subsidies, are used for actual industry emission reductions. Furthermore, monitoring should be conducted to ensure related funding is used efficiently.

Thirdly, international cooperation in the development of low-carbon technologies and the full use of foreign investment should be undertaken to promote innovation. In this process, domestic enterprises should be encouraged to reach out to other developing countries to engage in CDM projects 
and to compete and interact in the international carbon market. It is necessary to encourage foreign investment in China for the development of CDM projects and to harness the spillover effects generated by advanced technologies outside China during project implementation. Furthermore, the experiences of developed countries and regions in establishing a carbon market can be referenced to formulate relevant policies and systems in line with the conditions in China. Thus, the power of the international market can be appropriated to serve as a development model for promoting the internationalization of China's carbon market.

Fourth, using carbon emissions licenses, the development of carbon financial products can be implemented by referencing relevant early-stage experiences of other countries. Providing assorted carbon financial products to investors can assist them in diversifying risks, thereby increasing capital investment in the carbon market. Risks can be managed to maintain market stability and eventually lift restrictions in related trading.

The relationship between the carbon market and various entities should be adjusted in a timely manner to promote the development of carbon finance and radical low-carbon innovation as follows.

The relationship between the government and the market should be appropriately managed. The government should pay attention to market changes and apply scientific control to deliver satisfactory performance in the fields of finance, environmental protection, and science and technology. Relevant departments should fulfill their organizational, supervisory, and managerial responsibilities related to carbon finance. Information communication systems for trading carbon finance products should also be established to avoid information asymmetry in relevant trading. Additionally, by implementing a post assessment system for evaluating carbon finance policies, the timely and effective implementation of relevant policies can be ensured. Service support corresponding to the level of carbon finance development, free consulting services, should be provided to improve policy continuity and ensure policy stability. Through the establishment of a comprehensive information management system [51], details of the entities involved in carbon trading can be incorporated into an information database and updated in a timely manner to ensure the validity and integrity of carbon trading information. Regulatory authorities' concepts for supervising financial institutions should be regularly updated to be in line with the latest developments. The conventional gold standard of financial supervision should be changed, and the low-carbon economy and financial supervision should be thoroughly integrated; increased attention should also be paid to the effect of financial projects on the environment. At the same time, regulatory authorities should also focus on the development of carbon finance, increase the attention of financial institutions toward carbon finance, conduct risk assessments on the overall financial environment, and provide warnings when the risk of structural adjustments to the operations of financial institutions increase. By providing such a stable market environment, the influence of the carbon market on promoting radical low-carbon innovation can be enhanced.

Participation by intermediary institutions such as banks, insurance companies, securities companies, and mutual fund companies in the carbon market should be reinforced. Furthermore, the creation of Chinese institutions providing carbon emissions consultation, carbon rating, and carbon emission certification should be accelerated. Due to the delayed start of China's carbon market, up to two-thirds of the consultation services are being managed by foreign firms. Therefore, China must redouble its efforts in developing and training its own consulting and asset management companies.

The monitoring, reporting, and verification mechanisms for carbon dioxide emissions are indispensable for ensuring the rational allocation of carbon emission licenses. Currently, the number of institutions qualified to perform carbon emission verification in China is inconsistent with the number of CDM projects. In response to this situation, China should encourage the development of third-party verification agencies, develop a specific industry access system for them, and strengthen their management and internal control.

Regarding banking institutions in the carbon market, the Chinese government must formulate comprehensive credit rating-related legal and regulatory frameworks, accelerate the cultivation of 
China's independent credit rating agencies, and cultivate a world-class carbon credit rating system that meets the requirements of the global carbon market. Accordingly, China can have a voice and pricing power in the credit rating industry.

Radical low-carbon innovations are characterized by high cost, long research and development cycles, and high risks. Therefore, many small and medium-sized enterprises with insufficient financial resources should engage in cooperative programs for research and development, thereby sharing resources and risks. An innovation network should be chosen that is compatible with related resource and knowledge accumulation, simultaneously ensuring the dynamic stability of relationships and cooperation with other entities. Through an innovative cooperation network, the relationships between entities can be strengthened, which is conducive to the full utilization of all partners' resources, strengthening their complementary advantages, thereby improving capability and performance.

Author Contributions: Conceptualization and methodology, L.S.; software and writing-original draft preparation, J.W.; investigation and data curation, Z.W.; validation and writing-review and editing, L.M. All authors have read and agreed to the published version of the manuscript.

Funding: This article is funded by the Social Science Fund of the Educational Ministry of China (Grant no. 17YJC630131), and the National Social Science Fund of China (Grant no. 16BJL043).

Acknowledgments: We appreciate the software (used in our article) developed by: Borgatti, S.P., Everett, M.G. and Freeman, L.C. 2002. Ucinet for Windows: Software for Social Network Analysis. Harvard, MA: Analytic Technologies. Wilensky, U. (1999). NetLogo. http://ccl.northwestern.edu/netlogo/. Center for Connected Learning and Computer-Based Modeling, Northwestern University, Evanston, IL, USA.

Conflicts of Interest: The authors declare no conflict of interest.

\section{References}

1. Lu, S.; Ye, Y. Middle-income trap, comparative advantage trap, and comprehensive advantage strategy. Economist 2019, 7, 15-22.

2. Im, H.J.; Shon, J. The effect of technological imitation on corporate innovation: Evidence from US patent data. Res. Policy 2019, 48, 103802. [CrossRef]

3. Du, K.; Li, P.; Yan, Z. Do green technology innovations contribute to carbon dioxide emission reduction? Empirical evidence from patent data. Technol. Forecast. Soc. Chang. 2019, 146, 34-37. [CrossRef]

4. Morikawa, M. Innovation in the service sector and the role of patents and trade secrets: Evidence from Japanese firms. J. Jpn. Int. Econ. 2019, 51, 43-51. [CrossRef]

5. Ye, R.; Yang, J.; Chang, Y. Efficiency measurement and decomposition of China's provincial Hi-tech industry: A study based on a DEA model with shared inputs. J. Quant. Tech. Econ. 2012, 7, 3-17.

6. Jiang, G. A Comparative Study on the Patent Information in China between Domestic and Foreign Automobile Enterprises. In Proceedings of the 19th Annual Conference of the Chinese Journal of Management Science, Nanjing, China, 20 October 2017.

7. Deng, K.; Ding, Z. Why does China lack creative destruction?-Empirical evidence based on listed company attributes and information. Econ. Res. J. 2010, 45, 66-79.

8. Labatt, S.; White, R.R. Carbon Finance: The Financial Implications of Climate Change New Jersey; John Wiley \& Sons, Inc.: Hoboken, NJ, USA, 2012.

9. Sorrell, S.; Sijm, J. Carbon trading in the policy mix. Oxf. Rev. Econ. Policy 2003, 19, 420-437. [CrossRef]

10. Garcia, B.; Roberts, E. Carbon Finance-Environmental Market Solutions to Climate Change; Working Papers; Yale School of Forestry and Environmental Study: New Haven, CT, USA, 2008.

11. Li, Y.; Zhu, S.; Luo, L.; Yang, D. Theoretical exploration of low-carbon development as a macroeconomic objective-Based on China's situation. Manag. World 2017, 6, 1-8.

12. Eichner, T.; Pethig, R. Competition in emissions standards and capital taxes with local pollution. Reg. Sci. Urban Econ. 2018, 68, 191-203. [CrossRef]

13. Saltari, E.; Travaglini, G. Pollution control under emission constraints: Switching between regimes. Energy Econ. 2016, 53, 212-219. [CrossRef]

14. Sim, S.-G.; Lin, H.-C. Competitive dominance of emission trading over Pigouvian taxation in a globalized economy. Econ. Lett. 2018, 163, 158-161. [CrossRef] 
15. Yin, H.; Zhao, J.; Xi, X.; Zhang, Y. Evolution of regional low-carbon innovation systems with sustainable development: An empirical study with big-data. J. Clean. Prod. 2019, 209, 1545-1563. [CrossRef]

16. Pettifora, H.; Wilson, C.; Bogeleina, S.; Cassara, E.; Kerra, L.; Wilson, M. Are low-carbon innovations appealing? A typology of functional, symbolic, private and public attributes. Energy Res. Soc. Sci. 2020, 64, 101422. [CrossRef]

17. Zhou, K.; Li, Y. Carbon finance and carbon market in China: Progress and challenges. J. Clean. Prod. 2019, 214, 536-549. [CrossRef]

18. Jiang, Y.; Asante, D.; Zhang, J.; Cao, M. The effects of environmental factors on low-carbon innovation strategy: A study of the executive environmental leadership in China. J. Clean. Prod. 2020, 266, 121998. [CrossRef]

19. Maskus, K.E.; Neumann, R.; Seidel, T. How national and international financial development affect industrial R\&D. Eur. Econ. Rev. 2012, 56, 72-83.

20. Chowdhurya, R.H.; Maung, M. Financial market development and the effectiveness of R\&D investment: Evidence from developed and emerging countries. Res. Int. Bus. Financ. 2012, 26, 258-272.

21. Xu, Y.; Wang, H. Empirical analysis of China's financial development on technology innovation. Stat. Decis. 2011, 21, 144-146.

22. Zhang, Z. Financial Development, R\&D Innovation and Regional Technology Deepen. Econ. Rev. 2012, 3, $82-92$.

23. Hyytinena, A.; Toivanen, O. Do financial constraints hold back innovation and growth? Evidence on the role of public policy. Res. Policy 2005, 34, 1385-1403. [CrossRef]

24. Orman, C. Organization of innovation and capital market. N. Am. J. Econ. Financ. 2015, 33, 94-114. [CrossRef]

25. Stulz, R.M. Financial structure, corporate finance and economic growth. Int. Rev. Financ. 2000, 1, 11-38. [CrossRef]

26. Weinstein, D.; Yafeh, Y. On the costs of a bank-centered financial system: Evidence from the changing main bank relations in Japan. J. Financ. 1998, 53, 635-672. [CrossRef]

27. Li, X. Empirical Research on Government R\&D Funding, Financial Credit and Different Growth Stages of Enterprises. Manag. Rev. 2018, 30, 73-81.

28. Zhang, Y.; Gong, Q.; Rong, Z. Technological Innovation, Equity Financing, and Financial Structure Transition. J. Financ. Res. 2016, 11, 65-80.

29. Kortum, S.; Lerner, J. Assessing the contribution of venture capital to innovation. J. Econ. 2000, 31, 674-692. [CrossRef]

30. Atanassov, J.; Kanda, V.K.; Seru, A. Finance and Innovation: The Case of Publicly Traded Firms. Univ. Or. 2007, 1, 35-54. [CrossRef]

31. Lu, W. On Technological Innovation Principle of Venture Investment Mechanism. Econ. Res. J. 2002, 1, 48-56.

32. Sun, W.; Wang, P. Promotion of technology innovation by China's financial development. Manag. World 2013, 6, 172-173.

33. Xu, J.; Chen, S. The Study of Venture Capital's Principal-agent Model Based on Asymmetric Information. Syst. Eng. Theory Pract. 2004, 1, 19-24.

34. Cheng, C.C.J.; Chen, J.S. Breakthrough innovation: The roles of dynamic innovation capabilities and open innovation activities. J. Bus. Ind. Mark. 2013, 28, 444-454. [CrossRef]

35. Srivastava, M.K.; Gnyawali, D.R. When Do Relational Resources Matter? Leveraging Portfolio Technological Resources for Breakthrough Innovation. Acad. Manag. J. 2011, 54, 797-810. [CrossRef]

36. Fernández, Y.; FernándezLópez, M.A.; Blanco, B.O. Innovation for sustainability: The impact of R\&D spending on $\mathrm{CO}_{2}$ emissions. J. Clean. Prod. 2018, 172, 3459-3467.

37. Erzurumlu, S.S.; Erzurumlu, Y.O. Development and deployment drivers of clean technology innovations. J. High Technol. Manag. Res. 2013, 24, 100-108. [CrossRef]

38. Cheng, Z.; Li, L.; Liu, J. The emissions reduction effect and technical progress effect of environmental regulation policy tools. J. Clean. Prod. 2017, 149, 191-205. [CrossRef]

39. Wang, R.; Feng, Y.; Xu, H. The Influence of Reputation Resources and Relational Resources on Radical Innovation. J. Manag. Sci. 2017, 30, 87-101.

40. You, D.; Ma, B. Research on the influence of relationship fit on knowledge transfer and radical innovation performance. Syst. Eng. Theory Pract. 2014, 34, 3103-3112. 
41. Wang, Y.; Xie, W.; Wang, T.; Cheng, M. Research on the Relationship between Strong/Weak Ties and Radical Innovation: The Mediating Effect of Absorptive Capacity and Moderating Effect of Environmental Dynamism. Manag. Rev. 2016, 28, 111-122.

42. Pei, X.; Li, S.; Huang, Y. Study on the impact of involvement in fuzzy front end on radical innovation. Stud. Sci. Sci. 2015, 33, 460-470.

43. Wang, X.; Li, X.; Chen, G. Complex Networks Theory and Its Application; Tsinghua University Press: Beijing, China, 2006.

44. Xu, X.; Hao, J.; Deng, Y.; Wang, Y. Design optimization of resource combination for collaborative logistics network under uncertainty. Appl. Soft Comput. 2017, 560, 684-691. [CrossRef]

45. Xu, X.; Zhang, W.; Li, N.; Xu, H. A bi-level programming model of resource matching for collaborative logistics network in supply uncertainty environment. J. Frankl. Inst. 2015, 352, 3873-3884. [CrossRef]

46. Xu, X.; Hao, J.; Yu, L.; Deng, Y. Fuzzy Optimal Allocation Model for Task-Resource Assignment Problem in Collaborative Logistics Network. IEEE Trans. Fuzzy Syst. 2018, 99, 1-14. [CrossRef]

47. Bai, Z. Initiating urban public infrastructure complex network systems-A review of Integrated orderly supply and demand of urban public infrastructure systems. J. Tianjin Univ. Commer. 2019, 39, 73.

48. Chen, S.; Li, Y.; Shen, Q.; Ju, Y. Urban Traffic Networks Collaborative Optimization Method Based on Layered Complex Networks. J. Comput. Appl. 2019, 19, 1-11.

49. Luo, H.-Y.; Zhang, Q.-P. Index System Construction and Measurement of Radical Technological Innovation Capability of The Small Technology-based New Ventures under the Perspective of Knowledge Management. Oper. Manag. 2016, 25, 175-184.

50. Luo, Z. Government Funding, Enterprise R\&D Investment and Innovation Output—An Threshold Regression Analysis Based on the Evidence of Industrial Enterprises in Beijing. China Bus. Mark. 2018, 1, 102-112.

51. Zhang, Y.-X.; Cui, M.-Z. The impact of Corporate Social Responsibility on the enterprise value of China's listed coal enterprises. Extr. Ind. Soc. 2020, 7, 138-145. [CrossRef]

(C) 2020 by the authors. Licensee MDPI, Basel, Switzerland. This article is an open access article distributed under the terms and conditions of the Creative Commons Attribution (CC BY) license (http://creativecommons.org/licenses/by/4.0/). 